\title{
Attitude and Barriers of Community Pharmacists Towards Cancer Health Promotion: A Systematic Review
}

\author{
Kofi Boamah Mensah ${ }^{1,2}$, Frasia Oosthuizen ${ }^{2}$, Adwoa Bemah Bonsu ${ }^{3}$
}

${ }^{1}$ National Center for Radiotherapy \& Nuclear Medicine, Directorate of Oncology, Komfo Anokye Teaching Hospital,Ghana. ${ }^{2}$ Discipline of Pharmaceutical Sciences, College of Health Sciences, University of KwaZulu-Natal, Westville Campus, University Road, Durban,South Africa. ${ }^{3}$ Department of Nursing, College of Health Sciences, Kwame Nkrumah University of Science \& Technology, Ghana.

\begin{abstract}
Health promotion promotes quality of life and shows several positive outcomes for cancer patients and survivors. Studies indicate a decrease in mortality rates among women with breast cancer, improvement in the emotional state and quality of life among lung cancer patients. Community pharmacists are advocating, facilitating and providing cancer-related health promotions. This systematic review analyses attitude and barriers of community pharmacist towards cancer health promotion. Searches of major bibliographic databases identified primary studies published in English from 2005 to July 2017. A total of 323 records were identified and 5 were considered as been eligible based on the inclusion standard. Findings from the eligible studies revealed a favorable attitude of community pharmacists towards cancer health promotion but have perceived barriers towards it. The review was limited to five studies, hence regional or country studies will have to be carried out for an in-depth analysis of the attitude and barriers of community pharmacists and ways to address it.
\end{abstract}

Keywords: Cancer- health promotions- attitude- barriers- community pharmacists

Asian Pac J Cancer Care, 3 (1), 13-20

\section{Introduction}

\section{Background and Aim}

Over 8 million deaths occurred from cancer worldwide in 2013. As a result, it moved from the third major cause of death to the second major cause after cardiovascular diseases [1]. It is estimated that by 2030 , approximately 26 million new cancer cases and 17 million cancer deaths will occur globally [2].

Evidence from studies suggests that health promotion improves quality of life and demonstrated several positive outcomes for cancer patients and survivors [3] such as a decrease in mortality rates among women with breast cancer [4], improvement in the emotional state and quality of life among cancer patients [5]. The World Health Organization (WHO) has continually advocated the involvement of pharmacists in health promotion campaigns to raise awareness on health issues and disease prevention [6].
Submission Date: 10/23/2017Ａcceptance Date: 12/17/2017

Community pharmacists are the most widely accessible healthcare providers for almost all parts of the population (Abbott, Edwards, Whelan, Edwards, \& Dranitsaris, 2014). A 1985 Gallup poll indicated that they are the second most trusted healthcare personnel (Lum, McWaters, \& Mergener, 1989). In the community, they are the most approachable and reliable healthcare providers [7].

The scope of pharmacy practice has shifted from the traditional product-oriented service to patient-oriented activities (Anderson, 2007). The role of the pharmacist in cancer care is now rising with community pharmacists advocating, facilitating and providing cancer-related health promotion [8]. It is therefore important for community pharmacists to have extensive knowledge, positive attitudes, willingness and necessary tools to provide professional pharmaceutical care [9]. A limited number of studies have been done to assess the role of community pharmacists in providing public awareness

Corresponding Author:

Dr. Kofi Boamah Mensah

National Center for Radiotherapy \& Nuclear Medicine, Directorate of Oncology, Komfo Anokye Teaching Hospital,Ghana.

Discipline of Pharmaceutical Sciences, College of Health Sciences, University of KwaZulu-Natal, Westville Campus, University

Road, Durban,South Africa.

Email: kofimensah227@yahoo.co.uk 
about cancer diseases [10]. To achieve this, our aim was to conduct a systematic review that analyses attitude and barriers of community pharmacist towards cancer health promotion.

\section{Materials and Methods}

\section{Information Source and Search Strategy}

The literature search included studies from the following electronic bibliographic databases: EMBASE (Ovid), CINAHL (EBSCOhost) and MEDLINE (EBSCOhost). The search period was from 2005 to July 2017.

The Embase search strategy (Appendix1) combined keywords such as cancer, community pharmacist, attitude, barriers, and health promotion. The keywords were combined using Boolean terms, medical subject headings, and truncation. This search strategy was adopted for other database searches. Additional search from reference lists of articles selected for full-text review yielded no results.

The review was planned and carried out using the PRISMA (Preferred Reporting Items for Systematic Reviews and Meta-Analysis) checklist [11]. The protocol was registered with PROSPERO with registration number: CRD42017074328.

\section{Screening and Extraction Process}

All records were exported to and pooled in EndNote X7.0.2 software. Duplicates were identified and deleted using this reference management software. The title and abstract of the remaining articles were screened independently by two reviewers.

A standard table was used to extract data from the selected studies [12-14] and was later cross-checked for accuracy by a third reviewer. Data extracted included; lead author, year, country of study, sample description, type of cancer, duration of the study, study design, sample size, and conclusion.

\section{Results}

The database search yielded 323 records. Duplicates identified were deleted $(n=57)$. A total of 266 were screened on title and abstract. Irrelevant articles were excluded $(n=259)$. Relevant records $(n=17)$ were read fully and $(n=5)$ were considered eligible based on the set inclusion criteria. A flow chart summarising the selection procedure is shown in Figure 1.

\section{Characteristics of the Selected Studies}

The selected studies were conducted between the year 2010 and 2016 (Table 2). One of the studies were conducted in Africa (Tanzania) and four of the studies in the Middle East (Qatar, Malaysia, United Arab Emirate (UAE), Jordan). Data were obtained from community pharmacists except in one study that the data include other health care personnel [15]. All the studies were descriptive cross-sectional using researcher designed questionnaires. The type of cancers in the selected studies

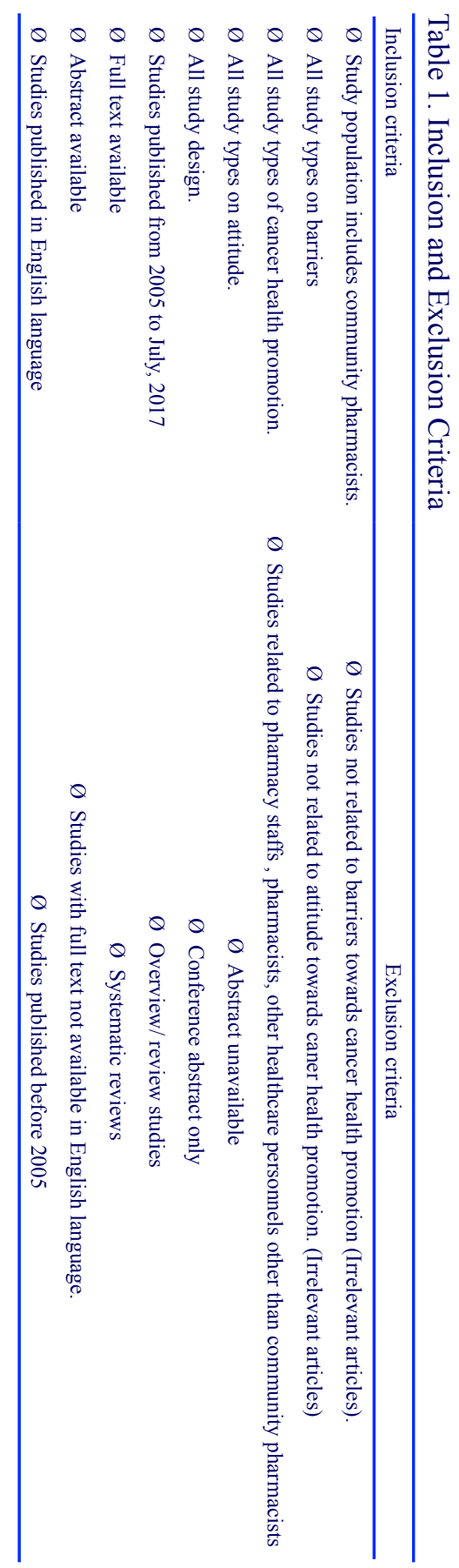

was Breast cancer. The sample size ranged between 35 [10] and 1000 [9].

\section{Quality Assessment of the Selected Studies}

The quality of the selected studies was assessed using a quality assessment tool (9). Score from $0 \%-33.9 \%$ is regarded as weak, $34 \%-66.9 \%$ is regarded as moderate and $67 \%-100 \%$ is regarded as strong. Based on this assessment tool, the quality level of all the selected studies was strong.

\section{Attitudes towards cancer health promotion}

Although attitudes towards cancer health promotion varied among community pharmacists in the selected studies, studies done in the Middle East reported 


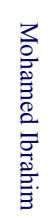<smiles>[CH]CCCCCCC</smiles><smiles>[Te][Te]</smiles><smiles>[C]1CCCCC1</smiles>

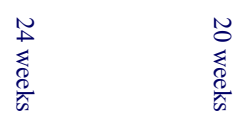<smiles>C1CCCCC1</smiles><smiles>[Tl]C1CCCCC1</smiles>

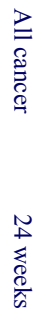<smiles>CC1[C@H](C)C[C@H]1C</smiles><smiles>[2H][C@H]1C[C@H]2C[C@H]1C2</smiles>

$\overline{\mathrm{s}}$

岕

ডั

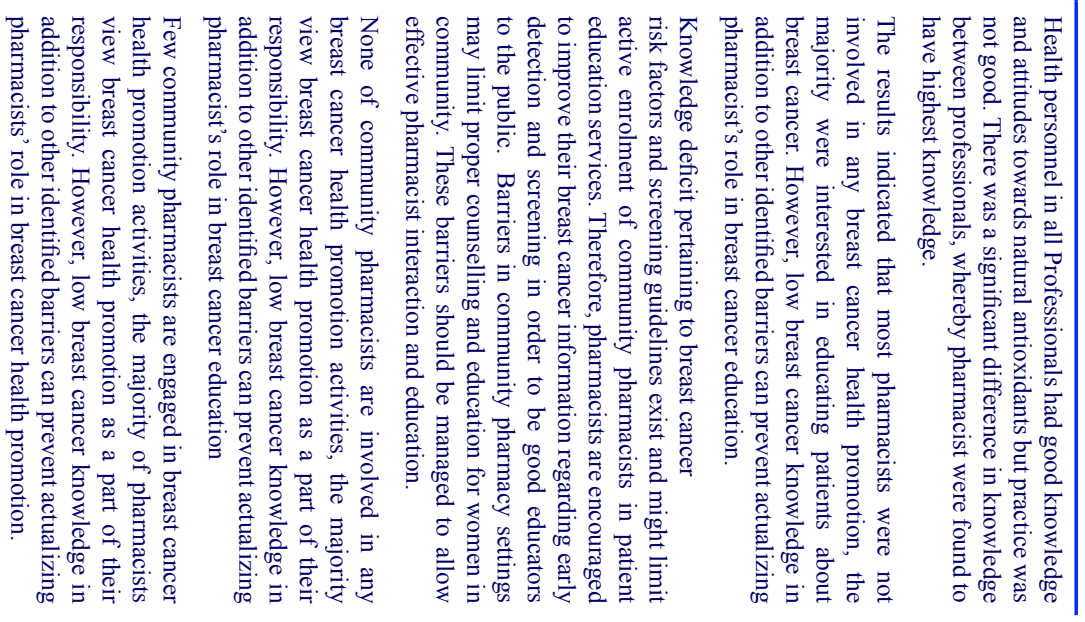


Table 3. Quality Assessment of Selected Studies

\begin{tabular}{|c|c|c|c|c|c|c|c|c|c|}
\hline & \multicolumn{5}{|c|}{ Quality Assessment items } & \multicolumn{2}{|c|}{ Relevance to Current Review } & \multirow[t]{2}{*}{ Score $(\%)$} & \multirow[t]{2}{*}{ Quality ranking } \\
\hline & A & B & $\mathrm{C}$ & $\mathrm{D}$ & $\mathrm{E}$ & $\mathrm{F}$ & G & & \\
\hline 15 & 0 & 1 & 1 & 1 & 1 & 1 & 0 & 71 & strong \\
\hline 16 & 1 & 1 & 1 & 1 & 1 & 1 & 1 & 100 & strong \\
\hline 9 & 1 & 1 & 1 & 1 & 1 & 1 & 1 & 100 & strong \\
\hline 10 & 1 & 1 & 1 & 1 & 1 & 1 & 1 & 100 & strong \\
\hline 17 & 1 & 1 & 1 & 1 & 1 & 1 & 1 & 100 & strong \\
\hline
\end{tabular}

Total score divided by the total number of items multiplied by 100; $0=$ No or not reported; $1=$ Yes; A—was sample likely to be representative of the study population?, B - Was a response rate mentioned within the study?, C — Was the instrument used reliable?, D — Was the instrument used valid?; E-Was it a primary data source?; F-Was attitude on cancer health promotion assessed?; G-Was barriers to cancer health promotionassessed?; Note. Quality assessment score and match with the objectives of the selected studies review: weak: $0-33.9 \%$, moderate: $34 \%-66.9 \%$, strong: $67 \%-100 \%$

overall attitude as favorable and study done in Africa demonstrated a positive attitude.

\section{Barriers towards cancer health promotion}

Perceived barriers for providing breast cancer health promotion reported in the selected studies were lack of breast cancer educational materials, lack of personnel, lack of public recognition of pharmacist's role, lack of time, lack of skills, lack of adequate knowledge, lack of direct profit, lack of training, lack of personnel, lack of budget and lack of reimbursement for such services. Only one study reported on gender barrier [10].

\section{Summary}

This review presents available evidence on attitudes and barriers towards cancer health promotion among community pharmacists. A study done by Murray and McMillan demonstrated that cancer remains the most feared disease in modern society [18]. Though the general public might be excused for their negative taught or attitude, one could assume that as a result of education, health professionals should have positive attitudes towards the disease.

The review shows that community pharmacists have a positive attitude toward breast cancer health promotion despite their actual poor involvement. Findings from the selected studies showed that community pharmacists hold a positive attitude because of their moderate to high level of knowledge on breast cancer. The selected study done in Tanzania showed that the majority of pharmacists had a positive attitude towards the use of antioxidants in cancer prevention due to their awareness about the usefulness of natural antioxidants [15].

Despite their low involvement in breast cancer health promotion activities, the majority of pharmacists were willing to be involved in educating their patients about breast cancer and viewed breast cancer health promotion as their responsibility. This goes in line with the findings which involved 485 community pharmacists in British Columbia concerning their level of participation in health education and disease prevention activities. It concluded that there is ample room for increasing pharmacist involvement in health education and disease prevention activities [19]. This means community pharmacists have the opportunity to improve upon their involvement in educating patients on cancer health promotion.

Majority of community pharmacists agreed that they should be involved in providing counseling, distributing breast cancer education materials, etc. as part of activities towards cancer health promotion. Counseling directed at behavioral and attitudinal change may

produce greater changes than traditional educational approaches to health promotion, particularly when tailored to the individual's readiness to change [20]. Hence provision of counseling services by community pharmacist will improve cancer health promotion in the community.

One of the selected studies done in the United Arab Emirates (UAE) indicates lack of patient's awareness of the type of services that pharmacists can offer, the type of counseling and education pharmacists are capable of delivering influence their attitude towards breast cancer health activities [17]. A marketing perspective would presuppose that cancer health promotion services might not be provided very intermittently due to lack of demand for these services. If patients are aware of cancer health promotion services could be made, community pharmacists or providers would devote labor, technology, and other resources to the provision of the service. Marketing perspective postulate that demand for a service depends on personal expectations and knowledge of the service [21]. There is evidence that exists indicating lack of patient's awareness of the type of services that pharmacists can offer. A study by Gagnon indicated that patients ranked of most professional services given by a pharmacist less important on average than pharmacists did. It was suggested in the study that patients may have been uninformed about the given by pharmacists [22]. This suggests that community pharmacist must create awareness and educate patients on the importance of breast cancer. This will influence the attitude of community pharmacist on breast cancer health promotion.

In this review, major factors that were identified as perceived barriers to cancer health promotion were lack of time, lack of educational materials, lack of privacy, lack of training, lack of personnel, lack of patients' appreciation for the role of the pharmacist as a breast cancer health promoter, gender, lack of profit and lack of budget. Lack of time is a barrier that stands against 


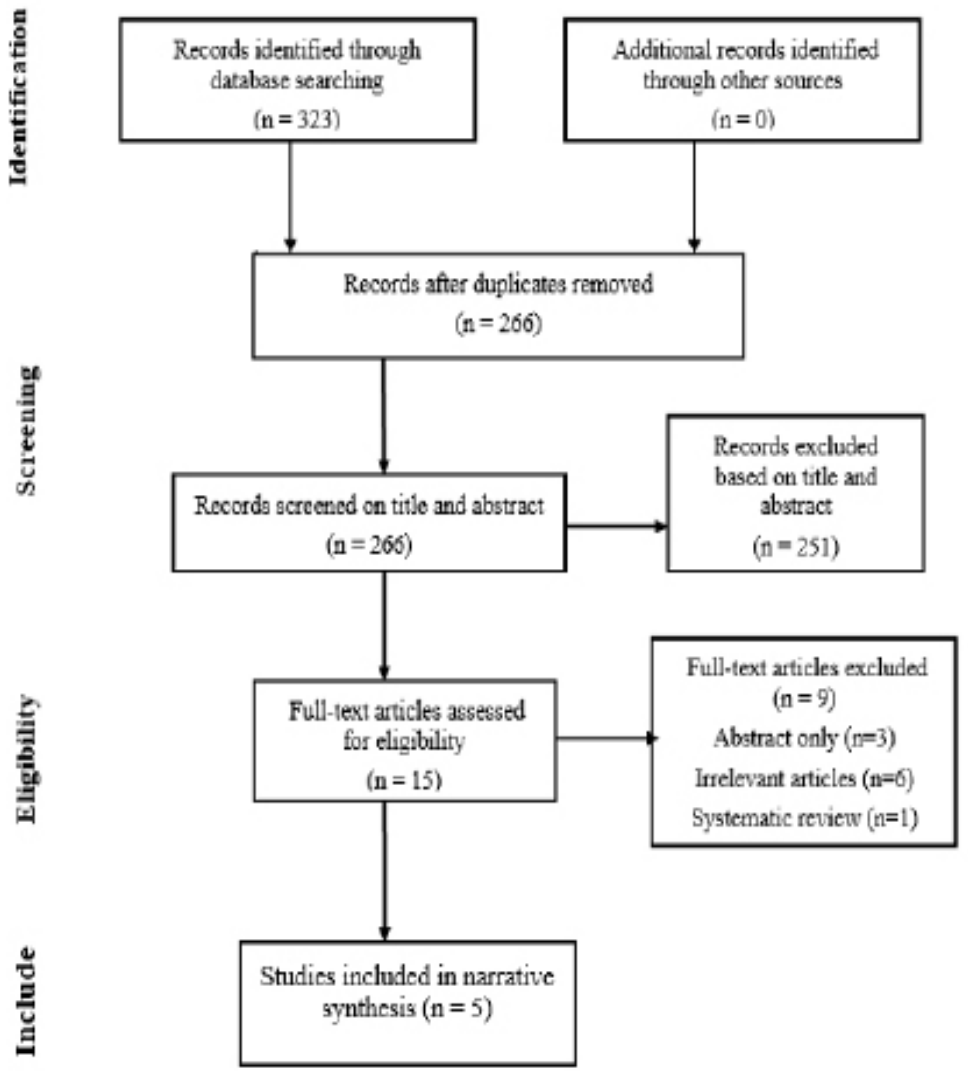

Figure.1

the provision of cognitive services by pharmacists' worldwide [23]. Community pharmacists in the selected studies perceived time as a barrier because of the lack of supporting staffs such as pharmacy technicians. This will interrupt their service delivery or daily activities if pharmacists are to provide breast cancer information to patients as their daily activities. The studies suggested for pharmacists to adequately provide breast cancer information to patients, without significant disruption to their daily activities, more pharmacy technicians need to be hired and better delineation should exist between the role of pharmacy technicians and that of pharmacists in this country.

The study done in Qatar indicated that lack of demand of breast cancer health promotion by patients as a barrier can be bypassed by educating the public about the pharmacist's role in health promotion and encouraging pharmacists to promote their abilities in this area [16].

Various researchers have identified that patients who are educated regarding the possibilities of pharmaceutical care are interested in receiving it. They are satisfied with the care they receive (24-26) and they are willing to pay for this services (27). Even though patients may need further information relating to their prescriptions, they do not fully understand this expanded role for pharmacists and how important it is for them. This difference in expectations can lead to pharmacists thwarted by lack of interest when a patient visits the pharmacy or patients frustrated by pharmacists' lack of attention when dispensing a prescription or a patient visit to the shop. By increasing patient expectations for their services, pharmacists can create an increase in demand for cancer health promotion services.

Lack of educational material was also perceived as a barrier to breast cancer education by Pharmacists in the selected studies. For effective patient education, community pharmacists should be provided with necessary tools, such as printed material, which can be easily provided to the public in work settings [9]. The role of cancer health information is often underestimated. It has a potential power in challenging the public to seek protective health services. An essential aspect of health promotion is to obtain accurate information. Access to accurate health information is important for progress toward reducing morbidity and mortality resulting from these cancers. Several studies in the mass media suggest that the public uses educational materials such as leaflets, fact, sheets, posters, and videos among others as their main sources of health information [28-29]. Access to accurate health information is crucial in enabling individuals to protect themselves from risk factors for diseases and conditions and in keeping up to date of existing cancer examinations or tests. It was reported in one of the selected studies that, to overcoming all perceived barriers, attention should be given to the education of undergraduate pharmacy students to ensure that they are well prepared for breast cancer health promotion [16]. The duration and composition of pharmacy education differ among countries [30-31]. Even though the basic pharmaceutical courses are similar, the pharmaceutical care concept is different with regards to the practice applied in the country [32-34]. Also, health care needs and standards of practice vary among countries as 
well as education. Thus, Pharmacy Education Taskforce of the World Health Organisation (WHO), United Nations Educational, Scientific, and Cultural Organization and the International Pharmaceutical Federation Global Pharmacy and the Education Action Plan 2008-2010 was developed. The action plan has four main areas of action namely quality assurance, academic and institutional capacity, competence, and vision for pharmacy education. The taskforce continuously monitors and disseminating evidence-based guidance and frameworks that facilitate the development of pharmacy education. This system in place will address or will be able to address this challenge or barrier.

Beshir and Hanipah [10] reported a lack of training as a major barrier that limits the involvement of community Pharmacists in breast cancer health promotion activities. Workplace training or learning plays an important part in the development of learners' attitudes, behaviors, and skills. The medical degree curriculum allows early integration of practice-based learning in the clinical environment [35]. Medical students are therefore exposed to the practice environment early in their career [36] through a range of clinical placements during undergraduate education or training [37]. The incorporation of practice-based training in the clinical setting from early on in the curriculum is an important part of a medical degree. The pharmacy profession is now clinical and patient-focused career but education and training have traditionally been very different from medicine. The pharmacy education and training require four years of training with relatively little practice exposure followed by 52 weeks of practice-based pre-registration training [38]. The pharmacy training may not prepare pharmacy graduates well for practice [39].

In conclusion, Results from this review indicate that most community pharmacists are not involved in cancer health promotion. Even though the majority are interested in educating patients particularly about breast cancer, there is low breast cancer knowledge in addition to other barriers that prevent the actualization of pharmacists' role in breast cancer health promotion. Therefore, further work should focus on evaluating community pharmacists' level of knowledge and educating them on general cancers to influence their involvement in cancer health promotion. Studies to overcome identified barriers should also be undertaken to help community pharmacist make an important contribution to cancer health promotion. Also, further studies should be undertaken to investigate barriers to general cancers and how to overcome them.

\section{Limitation}

The search was done using three databases and did not include data from the grey literature. The search was limited to studies conducted from 2005 to July 2017 and studies reported in English. These can result in study selection bias. Questionnaires used in the studies were designed by the studies investigators, hence resulting in heterogeneous results which cannot be combined for metaanalysis or meta-synthesis. Again some of the studies were self-reported surveys; hence the responses may be limited by some data inaccuracies resulting from intentional deception, poor recall of information, acquiescence (tendency to agree), extremity (tendency to use extreme ratings), misunderstanding of the question and may be biased by an inclination to provide socially desirable responses. The use of convenience sample in some of the selected studies could also create a selection bias which limits the generalizability of results. In one study, the survey was translated to Arabic via native speakers who are also fluent English speakers but this can affect the results since it was not validated and also different people will have the different interpretation to issues.

The studies were carried out only in breast cancer hence cannot be generalised for the other cancers. The review was limited to five studies, hence regional or country studies will have to be carried out for indepth analysis or picture of the attitude and barriers of community pharmacists and ways to address it.

\section{Abbreviations}

WHO: World Health Organisation

\section{Declarations: None}

Ethics approval and consent to participate: Not applicable.

\section{Consent for publication}

Not applicable

The authors declare that they have no financial and nonfinancial competing interests.

\section{Funding}

No financial support was sought in the production of this article.

\section{Availability of data and materials}

The datasets generated during the study are available in the figshare repository,

https://figshare.com/s/a12a3cb18f1899c3fa53

Available data was presented in the main manuscript. No supplementary data was generated.

\section{Authors' contributions}

All authors have made significant contributions in obtaining and analysis of the data. KB and

$\mathrm{FO}$ was involved in the data extraction and preparing the manuscript. FO and $\mathrm{KB}$ were involved in revising the manuscript critically for important intellectual content. Each author has performed sufficiently in the work and takes responsibility for appropriate portions of the content. $\mathrm{AB}$ was involved in reviewing the data and independently running the data extraction process. All authors have read and have given final approval of the study to be published.

\section{Acknowledgments}

\section{None}

\section{Author Details}

${ }^{1,2}$ National Center for Radiotherapy \& Nuclear Medicine, Directorate of Oncology, Komfo Anokye Teaching Hospital, Ghana. ${ }^{2}$ Discipline of Pharmaceutical Sciences, 
College of Health Sciences, University of KwaZuluNatal, Westville Campus, University Road, Durban, South Africa. ${ }^{3}$ Department of Nursing, College of Health Sciences, Kwame Nkrumah University of Science \& Technology, Ghana.

\section{References}

1. Naghavi M, Wang, H., Lozano, R., Davis, A., Liang, X., \& Zhou, M. (2015). GBD 2013 Mortality and Causes of Death Collaborators. Global, regional, and national age-sex specific all-cause and cause-specific mortality for 240 causes of death, 1990-2013: a systematic analysis for the Global Burden of Disease Study 2013. Lancet, .385((9963), ):117-71. .

2. Boyle P, Levin B. World cancer report 2008: IARC Press, International Agency for Research on Cancer; 2008.

3. Meraviglia M, Stuifbergen A, Morgan S, Parsons D. Lowincome cancer survivors' use of health-promoting behaviors. MedSurg Nursing. 2015;24(2):101-7.

4. Holmes MD, Chen WY, Feskanich D, Kroenke CH, Colditz GA. Physical activity and survival after breast cancer diagnosis. Jama. 2005;293(20):2479-86.

5. Chen H, Tsai C, Wu Y, Lin K, Lin C. Randomised controlled trial on the effectiveness of home-based walking exercise on anxiety, depression and cancer-related symptoms in patients with lung cancer. British journal of cancer. 2015;112(3):438.

6 . World Health Organization. The role of the pharmacist in selfcare and self-medication. Geneva: WHO. 1998.

7. Hourihan F, Krass I, Chen T. Rural community pharmacy: a feasible site for a health promotion and screening service for cardiovascular risk factors. Australian Journal of Rural Health. 2003;11(1):28-35.

8. Calis KA, Hutchison LC, Elliott ME, Ives TJ, Zillich AJ, Poirier T, et al. Healthy People 2010: challenges, opportunities, and a call to action for America's pharmacists. Pharmacotherapy. 2004;24(9):1241-94.

9. Ayoub NM, Nuseir KQ, Othman AK, Abu Alkishik S. Knowledge, attitudes and barriers towards breast cancer health education among community pharmacists. Journal of Pharmaceutical Health Services Research. 2016;7(3):18998.

10. Beshir S, Hanipah M. Knowledge, perception, practice and barriers to breast cancer health promotion activities among community pharmacists in two Districts of Selangor state, Malaysia. Asian Pacific Journal Of Cancer Prevention: APJCP. 2012;13(9):4427-30.

11. Liberati A, Altman DG, Tetzlaff J, Mulrow C, Gøtzsche PC, Ioannidis JP, et al. The PRISMA statement for reporting systematic reviews and meta-analyses of studies that evaluate healthcare interventions: explanation and elaboration. PLoS medicine. 2009;6(7):e1000100.

12. Goossens J, Delbaere I, Van Lancker A, Beeckman D, Verhaeghe S, Van Hecke A. Cancer patients' and professional caregivers' needs, preferences and factors associated with receiving and providing fertility-related information: a mixed-methods systematic review. International journal of nursing studies. 2014;51(2):300-19.

13. Saab M, Landers M, Hegarty J. Males' awareness of benign testicular disorders: an integrative review. American journal of men's health. 2016:1557988315626508.

14. Saab M, Landers M, Hegarty J, editors. Testicular Cancer Awareness and Screening Practices: A Systematic Review. Oncology nursing forum; 2016.

15. Malele RRS, Sayuni N. Assessment of knowledge, attitude, and practice on the use of natural antioxidants towards cancer prevention among health personnel at Muhimbili. Research Journal of Pharmaceutical, Biological, and Chemical Sciences. 2014;5(1):962-79.

16. El Hajj MS, Hamid Y. Breast cancer health promotion in Qatar: a survey of community pharmacists' interests and needs. International journal of clinical pharmacy. 2011;33(1):70-9.

17. Ibrahim OHM, Ibrahim RM. COMMUNITY PHARMACISTS'INVOLVEMENT IN BREAST CANCER HEALTH PROMOTION IN UNITED ARAB EMIRATES (UAE). American Journal of Pharmacology and Toxicology. 2013;8(4):155.

18. Murray M, McMillan CL. Gender differences in perceptions of cancer. Journal of Cancer Education. 1993;8(1):53-62.

19. Paluck EC, Stratton TP, Eni GO. Community pharmacists' participation in health education and disease prevention activities. Canadian Journal of public health= Revue Canadienne de Sante Publique. 1994;85(6):389.

20. Calfas KJ, Long BJ, Sallis JF, Wooten WJ, Pratt M, Patrick $\mathrm{K}$. A controlled trial of physician counseling to promote the adoption of physical activity. Preventive medicine. 1996;25(3):225-33.

21. Huotari K, Hamari J, editors. Defining gamification: a service marketing perspective. Proceeding of the 16th International Academic MindTrek Conference; 2012: ACM.

22. Gagnon JP. Store Distributed Surveys as a Source of Consumer Feedback on Pharmacy Services. Journal of Consumer Affairs. 1978;12(2):333-42.

23. Keene J, Cervetto S. Health promotion in community pharmacy: a qualitative study. Health Education Journal. 1995;54(3):285-93.

24. Bultman DC, Svarstad BL. Effects of pharmacist monitoring on patient satisfaction with antidepressant medication therapy. Journal of the American Pharmaceutical Association (1996). 2002;42(1):36-43.

25. Kradjen WA, Schulz R, Christensen DB, Stergachis A, Sullivan S, Fullerton DP, et al. Patients' perceived benefit from and satisfaction with asthma-related pharmacy services. Journal of the American Pharmaceutical Association (1996). 1999;39(5):658-66.

26. Johnson KA, Parker JP, McCombs JS, Cody M. The Kaiser Permanente/USC patient consultation study: patient satisfaction with pharmaceutical services. The University of Southern California. American journal of health-system pharmacy. 1998;55(24):2621-9.

27. Assa-Eley M, Kimberlin CL. Using interpersonal perception to characterize pharmacists' and patients' perceptions of the benefits of pharmaceutical care. Health Communication. 2005;17(1):41-56.

28. Chung V, Horowitz AM, Canto MT, Siriphant P. Oral cancer educational materials for the general public: 1998. Journal of public health dentistry. 2000;60(1):49-52.

29. Connell CM, Crawford CO. How people obtain their health information--a survey in two Pennsylvania counties. Public Health Reports. 1988;103(2):189.

30. Al-Wazaify M, Matowe L, Albsoul-Younes A, Al-Omran OA. Pharmacy education in Jordan, Saudi Arabia, and Kuwait. American journal of pharmaceutical education. 2006;70(1):18.

31. Kheir N, Zaidan M, Younes H, El Hajj M, Wilbur K, Jewesson PJ. Pharmacy education and practice in 13 Middle Eastern countries. American journal of pharmaceutical education. 2008;72(6):133.

32. Sosabowski MH, Gard PR. Pharmacy education in the United Kingdom. American journal of pharmaceutical education. 2008;72(6):130.

33. Marriott JL, Nation RL, Roller L, Costelloe M, Galbraith 
$\mathrm{K}$, Stewart P, et al. Pharmacy education in the context of Australian practice. American journal of pharmaceutical education. 2008;72(6):131.

34. Bourdon O, Ekeland C, Brion F. Pharmacy education in France. American journal of pharmaceutical education. 2008;72(6):132.

35. General Medical Council Education Committee. Tomorrow's doctors: recommendations on undergraduate medical education: General Medical Council London; 1993.

36. Spencer J, Blackmore D, Heard S, McCrorie P, McHaffie $\mathrm{D}$, Scherpbier A, et al. Patient oriented learning: a review of the role of the patient in the education of medical students. Medical education. 2000;34(10):851-7.

37. Swanwick T. Understanding medical education: Evidence, theory, and practice: John Wiley \& Sons; 2013.

38. Schafheutle E, Hassell K, Ashcroft D, Hall J, Harrison S. Learning professionalism in the Mpharm-what role does 'organisational philosophy'play? International Journal of Pharmacy Practice. 2010;18:19-20.

39. MCAteer S, John D, Luscombe D. Views of pre-registration graduates on the UK pharmacy undergraduate course as preparation for pre-registration training. International Journal of Pharmacy Practice. 2004; 12: R61-R.

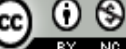

This work is licensed under a Creative Commons AttributionNon Commercial 4.0 International License. 